\title{
Greenhouse Gas-Induced Changes in Summer Precipitation over Colorado in NARCCAP Regional Climate Models*
}

\author{
Michael A. AleXANDER \\ NOAA/Earth System Research Laboratory, Boulder, Colorado \\ JAmes D. Scott, Kelly MAHONey, AND Joseph BARSUgli \\ NOAA/Earth System Research Laboratory, and Cooperative Institute for Research in Environmental Sciences, \\ University of Colorado Boulder, Boulder, Colorado
}

(Manuscript received 8 February 2013, in final form 26 June 2013)

\begin{abstract}
Precipitation changes between 32-yr periods in the late twentieth and mid-twenty-first centuries are investigated using regional climate model simulations provided by the North American Regional Climate Change Assessment Program (NARCCAP). The simulations generally indicate drier summers in the future over most of Colorado and the border regions of the adjoining states. The decrease in precipitation occurs despite an increase in the surface specific humidity. The domain-averaged decrease in daily summer precipitation occurs in all of the models from the 50th through the 95th percentile, but without a clear agreement on the sign of change for the most extreme (top 1\% of) events.
\end{abstract}

\section{Introduction}

Global climate models (GCMs) indicate that that increasing anthropogenic greenhouse gases (GHGs) will cause the earth to warm and will enhance precipitation in tropical and polar regions while decreasing it in the subtropics (e.g., Meehl et al. 2007). In the United States, GCMs also indicate that the Southwest will dry and the Northwest will become wetter over the course of the twenty-first century because of a number of factors, including the expansion of the Hadley cell and northward shift of the storm track (e.g., Seager et al. 2007; Seager and Vecchi 2010; Yin 2005). In addition, the percentage of rain falling in the heaviest events is generally projected to increase, or as stated more explicitly in the Intergovernmental Panel on Climate Change's special report on extremes, "[ $\mathrm{t}]$ here is medium confidence that, in some

\footnotetext{
* Supplemental information related to this paper is available at the Journals Online website: http://dx.doi.org/10.1175/JCLI-D-1300088.s1.

Corresponding author address: Michael Alexander, NOAA/ Earth System Research Laboratory, R/PSD1, 325 Broadway, Boulder, CO 80305.

E-mail: michael.alexander@noaa.gov
}

regions, increases in heavy precipitation will occur despite projected decreases in total precipitation in those regions" (Field et al. 2012, p. 13).

While there is general agreement among the models for thermal and moisture changes at continental scales, GCMs diverge at regional and smaller scales as a result of their coarse resolutions (approximately $100-300 \mathrm{~km}$ ), parameterizations of subgrid-scale processes, and natural climate variability. For example, GCMs tend to overestimate the mean winter precipitation over the western United States because of an overly strong jet stream/storm track and a lack of rain shadow in the lee of the Sierra Nevada and Cascade Mountains (McAfee et al. 2011). Such biases likely impact the models' response to increases in GHGs. Regional climate models (RCMs), with resolutions of $40-60 \mathrm{~km}$, may be able to correct for some of these deficiencies and provide a better representation of midlatitude storms and hydrology in mountainous regions including extreme precipitation events (Leung et al. 2004; Wehner et al. 2010; Gao et al. 2011, 2012).

The North American Regional Climate Change Assessment Program (NARCCAP; Mearns et al. 2009, 2012) has produced multiple model simulations used in several recent studies to investigate climate variability and change. NARCCAP includes a suite of RCMs forced 
on the boundaries by output from either National Centers for Environmental Prediction (NCEP) Reanalysis 2 (Kanamitsu et al. 2002) or multiple GCMs to simulate the recent past. Several aspects of the observed climate over the western United States are well simulated in the NARCCAP simulations, including the semiannual cycle of precipitation (Wang et al. 2009), the amount of extreme precipitation for a coastal California region and the associated 500-hPa circulation anomaly (Gutowski et al. 2010), and some aspects of the temperature trends, especially those in winter and spring (Bukovsky 2012). While the spatial pattern of precipitation over the western United States is generally realistic, its winter mean and annual cycle tend to be excessive (Wang et al. 2009; Dominguez et al. 2012).

NARCCAP also included RCM simulations driven by GCM fields during a twenty-first-century period, and several studies have used these experiments to investigate climate change over the western United States by comparing the climate in the two periods: 1969-2000 and 2039-70. Dominguez et al. (2012) found a decrease in the mean twenty-first-century precipitation over the Southwest, but a statistically significant increase in the intensity of extreme precipitation over much of the western United States in most models during winter. Wehner (2013) noted that the multimodel average indicated a statistically significant decrease in mean precipitation in the Southwest in the spring and the western United States during summer, where the seasonal maxima in precipitation and their 20-yr return values follow the same general spatial pattern as the mean changes but vary considerably between models. Over the Colorado River basin, the projected mid-twenty-first-century runoff changes are primarily affected by the combination of snow cover change in winter, temperature change in spring, and precipitation change in summer (Gao et al. 2011). The changes in the high plains and Rocky Mountains appear to be more variable across models, as this region is near the node between projected wet and dry changes. The response to increases in greenhouse gas forcing over Colorado may differ from other parts of the western United States because it is influenced by moisture originating from the Gulf of Mexico as well as the Pacific Ocean, and interacts with a wide variety of topographic features, some with very sharp gradients that are subject to small-scale but intense convective precipitation events during summer.

Here, we use the GCM-driven NARCCAP experiments to examine precipitation changes over Colorado and the border regions of surrounding states with a focus on summer. While much of the precipitation over the Rocky Mountains falls during the winter, the eastern plains of Colorado receive most of their annual precipitation during the summer and the Front Range corridor experiences a primary or secondary maximum in precipitation during July and August. Summer precipitation is important due to its impact on residential and agricultural water demand, severe weather, extreme heat, drought, and wildfire (Ray et al. 2006).

\section{Model simulations and observations}

NARCCAP is a multi-institutional effort that uses multiple RCMs nested within GCMs to simulate climate variability and change over North America (Mearns et al. 2009, 2012). The GCM-RCM combinations are used to simulate separate $32-\mathrm{yr}$ periods in the twentieth and twenty-first centuries: 1969-2000 and 2039-70. The twenty-first-century experiments utilize the A2 scenario for greenhouse gases, in which $\mathrm{CO}_{2}$ levels increase to $\sim 600$ ppm by 2070 . The four RCMs, which have a common domain covering the continental United States, Canada, northern Mexico, and most of Alaska (see Fig. S1a in the supplemental material), are the Canadian Regional Climate Model (CRCM); the Met Office Hadley Centre's Hadley Regional Model, version 3 (HRM3); the Regional Climate Model, version 3 (RCM3); and the Weather Research and Forecasting Model with the Grell convection scheme (WRFG). Though the model grids differ, they all use a grid spacing of approximately $50 \mathrm{~km}$. Lateral boundary conditions for the RCMs are taken without bias correction from four GCMs: the National Center for Atmospheric Research (NCAR) Community Climate System Model, version 3 (CCSM; the " 3 " is excluded following the NARCCAP naming convention); the Canadian Centre for Climate Modelling and Analysis Coupled General Circulation Model, version 3 (CGCM3); the Hadley Centre Coupled Model, version 3 (HadCM3); and the Geophysical Fluid Dynamics Laboratory Climate Model, version 2.1 (GFDL CM2.1). While the NARCCAP experiment design entails 12 GCM-RCM combinations [see Mearns et al. (2012)], we used all seven GCM-RCM combinations that were available at the time of this study: CCSM-CRCM, CCSM-WRFG, CGCM3-CRCM, CGCM3-WRFG, CGCM3-RCM3, HadCM3-HRM3, and GFDL CM2.1-RCM3 (hereafter GFDL-RCM3). An additional global high-resolution $(50 \mathrm{~km})$ experiment was performed using the atmospheric model component (AM2) of the GFDL CM2.1. In this "time slice" GFDL AM2 experiment, observed SSTs and sea ice are used as lower boundary conditions in the AM2 during 1969-2000, and the same boundary conditions but with the addition of twenty-first-century minus twentiethcentury values from the GFDL CM2.1 simulation were used during 2039-70. One simulation was conducted for the twentieth- and twenty-first-century periods for each of 


\section{JJA Precip 20th Century Climate ( $\mathrm{mm} / \mathrm{season})$}
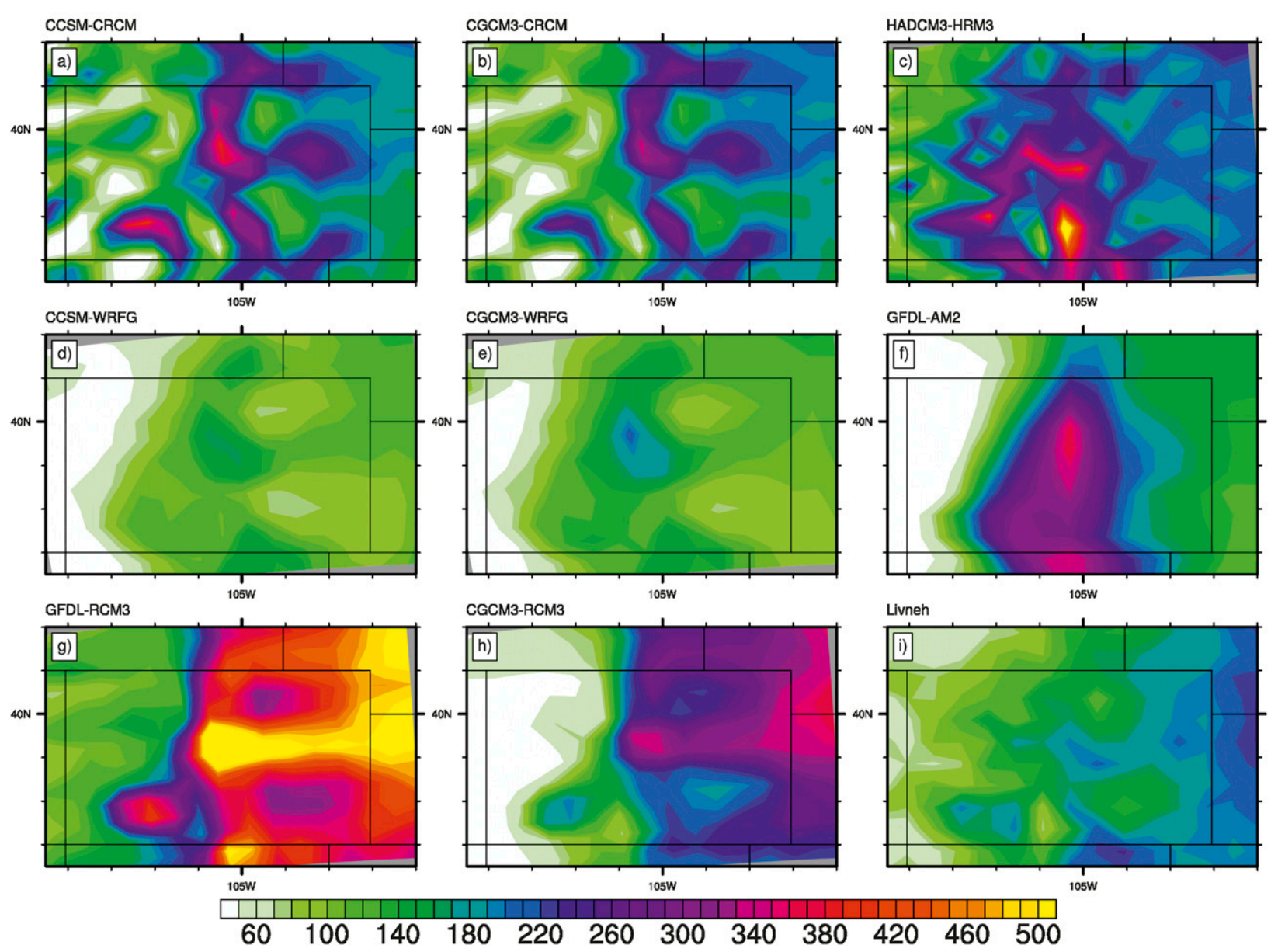

FIG. 1. JJA precipitation ( $\mathrm{mm}$ ) averaged over the twentieth-century period (1969-2000) for the study region (Colorado and the border areas of the surrounding states) for the eight NARCCAP simulations: (a) CCSM-CRCM, (b) CGCM3-CRCM, (c) HadCM3-HRM3, (d) CCSM-WRFG, (e) CGCM3-WRFG, (f) GFDL AM2, (g) GFDL-RCM3, and (h) CGCM3-RCM3. (i) Observations obtained from Livneh et al. (2013) averaged to the RCM grid scale by bilinear interpolation.

the eight model configurations, and the model output is available at 3 -h intervals.

For the twentieth-century period, precipitation values from the eight simulations are compared to values from a high-resolution dataset recently developed by Livneh et al. (2013). The latter, available on a $1 / 16^{\circ}$ latitudelongitude grid over the conterminous United States for the years 1915-2011, is an updated version of the Maurer et al. (2002) dataset and derived using daily observations from approximately 20000 National Oceanic and Atmospheric Administration (NOAA) Cooperative Observer stations. The daily data are rescaled so that the long-term monthly climatology equals that from the Parameter-Elevation Regressions on Independent Slopes Model (PRISM; Daly et al. 1994). Precipitation values obtained from the North American Regional Reanalysis
(NARR; Mesinger et al. 2006) for the twentieth century were very similar to those obtained from the Livneh data for all of the analyses performed here and thus are not shown.

\section{Results}

The mean precipitation during summer [June-August (JJA)] during the 1969-2000 period from the eight NARCCAP simulations and the Livneh dataset are shown in Fig. 1 for the study region (Fig. S1 in the supplemental material). The heaviest observed precipitation in Colorado occurs in the northeastern part of the domain, where it reaches $\sim 240 \mathrm{~mm}$ in JJA (Fig. 1i). Heavier precipitation $(>160 \mathrm{~mm})$ occurs along the Front Range of the Rocky Mountains at $\sim 105^{\circ} \mathrm{W}$ from northern 


\section{JJA Precip averaged over Colorado}

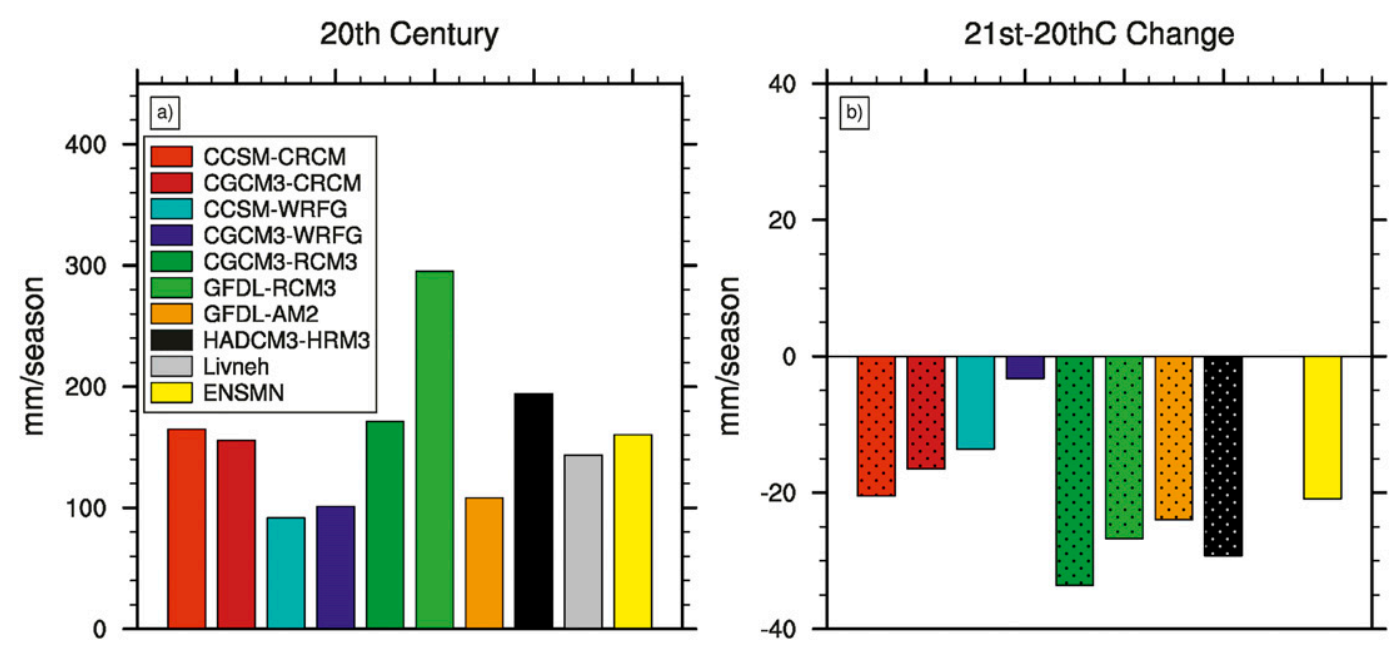

FIG. 2. JJA-mean precipitation $(\mathrm{mm})$ averaged over Colorado and the border areas of the surrounding states for (a) the twentieth century (1969-2000) and (b) the twenty-first century (2039-70) minus the twentieth century (19692000) for the eight NARCCAP simulations and the ensemble mean (ENSMN). Precipitation from the Livneh dataset for 1969-2000 is also shown in (a), while the twenty-first-century minus twentieth-century values that are significant at the $95 \%$ level as determined by Monte Carlo method based on 1000 resamples are stippled in (b).

New Mexico to southern Wyoming, over the Palmer Divide at $\sim 39^{\circ} \mathrm{N}$ extending east from $105^{\circ} \mathrm{W}$, over the Cheyenne and Raton Ridges that are located along the northern and southern borders of eastern Colorado, and in the San Juan Mountains located in southwest Colorado (see Fig. S1b in the supplemental material). The GCMdriven RCMs or "models" simulate aspects of the general precipitation pattern and reflect the broadscale topographic influence on precipitation, that is, the pattern correlation between the models and observations ranges from 0.55 to 0.87 (Table S1 in the supplemental material) with an average of 0.71 , and most are drier in the western and wetter in the eastern part of the domain, with a maximum over the Front Range and secondary maximum along the Palmer Divide and the Cheyenne and Raton Ridges. However, more detailed spatial structures differ from observations, and the pattern and magnitude of the simulated values vary widely (also see Fig. 2a). The models also have excessive precipitation over the mountains with the exception of the two WRFG simulations. The model precipitation is influenced by a number of factors, including the horizontal and vertical resolution and model physics, which include parameterizations for convection, cloud microphysics, and boundary layer processes (see, e.g., Mahoney et al. 2013). The summer precipitation appears to be largely governed by the regional processes in the RCMs, as simulations utilizing the same RCM have similar spatial patterns despite being forced by different GCM boundary conditions (see Table S1 in the supplemental material).
The differences in the mean summer precipitation between the future (2039-70) and recent (1969-2000) periods are shown in Figs. $2 \mathrm{~b}$ and 3 . All of the models indicate drying for the domain average (Fig. 2b), which is significant at the $95 \%$ level for six of the eight models. The twenty-first-century precipitation decreases by about $20 \mathrm{~mm}(\sim 13 \%)$ when averaged across the eight simulations (Fig. 2b and Fig. S2 in the supplemental material). The change in the precipitation pattern, however, is variable: the CCSM-CRCM, CCSM-WRFG, CGCM3CRCM, HadCM3-HRM3, and CGCM3-RCM3 indicate decreased precipitation over nearly all of the domain; the GFDL AM2 and GFDL-RCM3 show reduced precipitation in the east and increase in the west; and the CGCM3-WRFG indicate drying in western Colorado and a slight increase in precipitation along the Colorado borders east of $\sim 105^{\circ} \mathrm{W}$. The drying over the southern Front Range and Palmer Divide is fairly consistent across the models, with from four to five models showing significant differences (at the 95\% level as indicated by 1000 Monte Carlo samples) between the two periods (Fig. 3i).

The twenty-first-century minus twentieth-century nearsurface specific humidity during summer is positive over the entire domain in all of the NARCCAP simulations, with the largest increase generally occurring in the northeast portion of the domain (Fig. 4). There is not a strong correspondence between the change in mean low-level moisture and precipitation (Fig. 3), that is, the precipitation decreases even though the moisture increases, with 


\section{JJA Precip 21st-20th Century Climate Change ( $\mathrm{mm} / \mathrm{season})$}
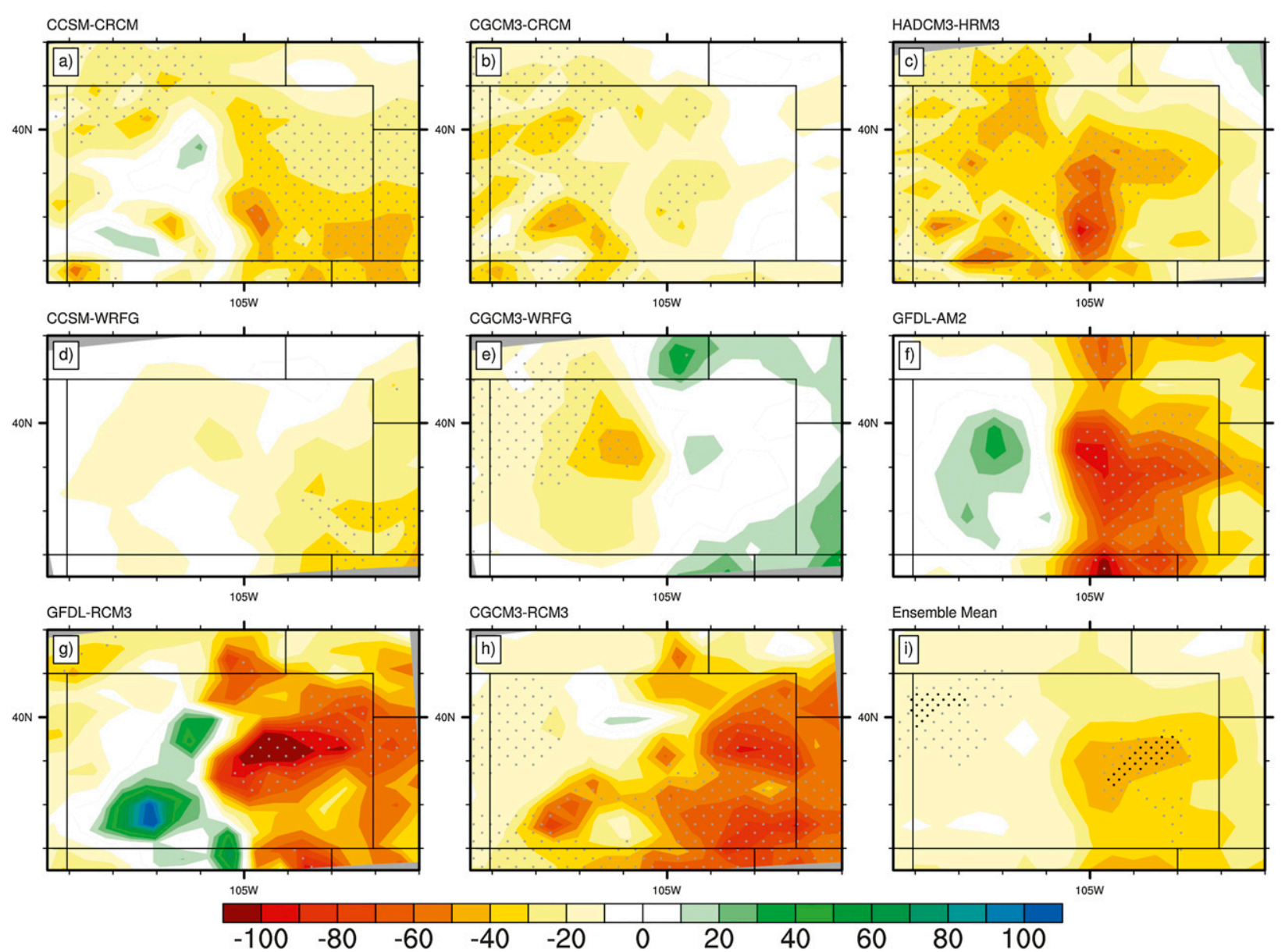

FIG. 3. Twenty-first-century minus twentieth-century mean JJA precipitation (mm) from (a)-(h) the eight NARCCAP simulations and (i) their ensemble mean. In (a)-(h), stippling indicates regions where the difference values are significant at the $95 \%$ level based on 1000 Monte Carlo samples, while in (i), gray (black) stippling denotes grid squares where at least four (five) of the individual models indicate a significant change and have the same change in sign.

no clear correspondence between the patterns in the two fields.

The daily precipitation during JJA averaged over the individual grid points within the domain is presented as a function of the percentile (\%) in Fig. 5. Note that the precipitation amounts for a given percentile are obtained at each grid point first and then averaged over the domain and that the percentiles are relative to all days during the periods considered, not just the rainy days, as is commonly done. One advantage of the latter is that the percentile categories translate directly to return periods, regardless of the number of rainy days. For example, the 99th percentile corresponds to an event that happens approximately once a summer on average. Precipitation amounts during 1969-2000 for the NARCAPP simulations and the Livneh data are presented in Fig. 5a for the 50-99.5th percentiles (more than half the days have from little to no precipitation). The models, which bracket the observations, range from about 1 to 4,3 to 10 , and 10 to $38 \mathrm{~mm} \mathrm{day}^{-1}$ at $80 \%, 90 \%$, and $99 \%$, respectively. The difference in the daily precipitation averaged over Colorado from $50 \%$ to $99 \%$ (Fig. 5 b) indicates a future decrease in all models below the $95 \%$. Above $95 \%$ the models widely diverge, with the GFDL-RCM3 and the CGCM3-WRFG showing enhanced precipitation above $\sim 98 \%$, while the GFDL AM2 and CGCM-RCM3 continued decreases in precipitation above $95 \%$. This disparity also occurs if the precipitation in each grid square is first normalized by its JJA mean and arises in both the western/mountainous and eastern/plains if the domain is divided into two separate regions (Fig. S5 in the supplemental material). The wide disparity between the 


\section{JJA Sfc Specific Humidity 21st-20th Century Climate Change (g/kg)}
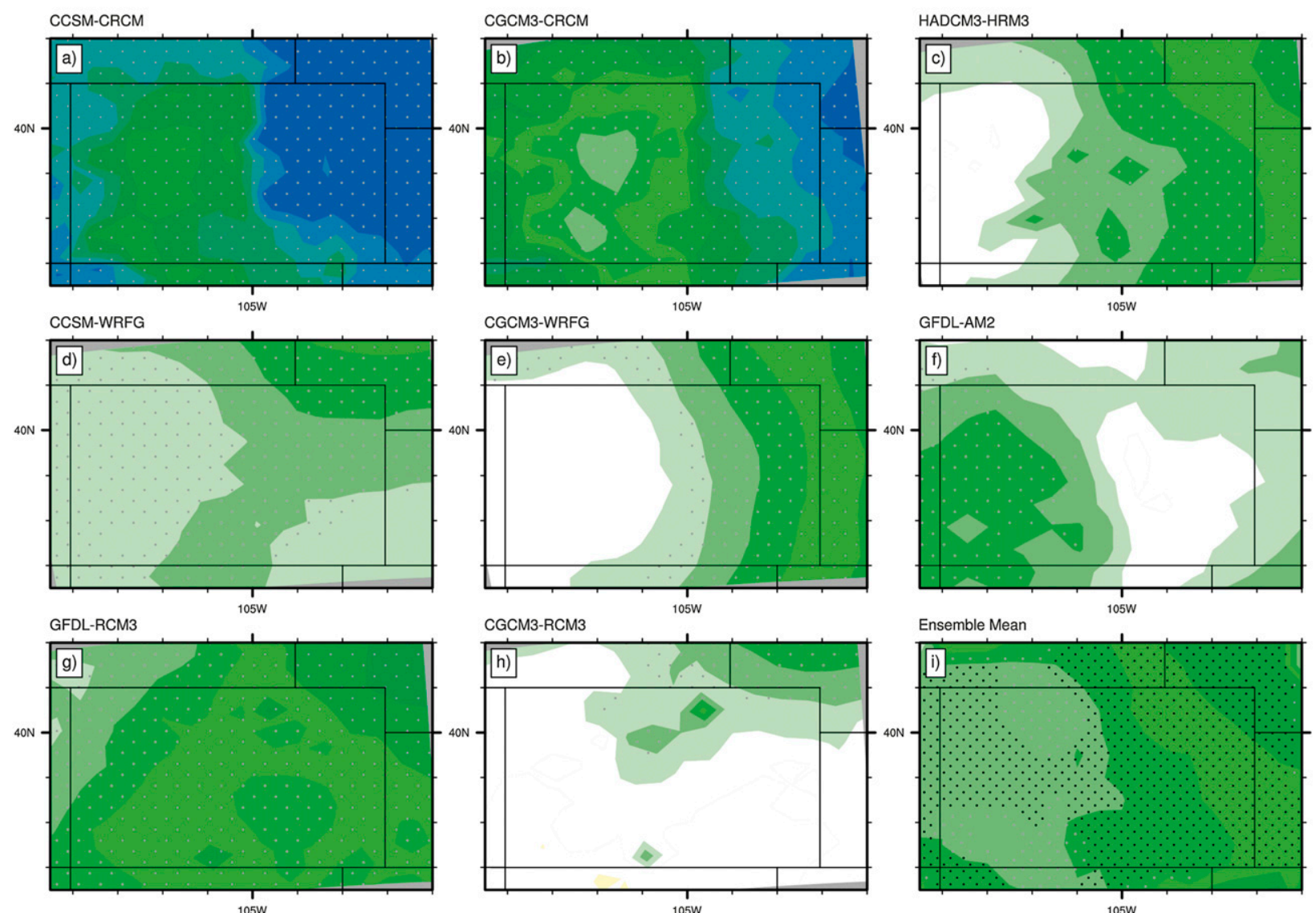

CGCM3-RCM3

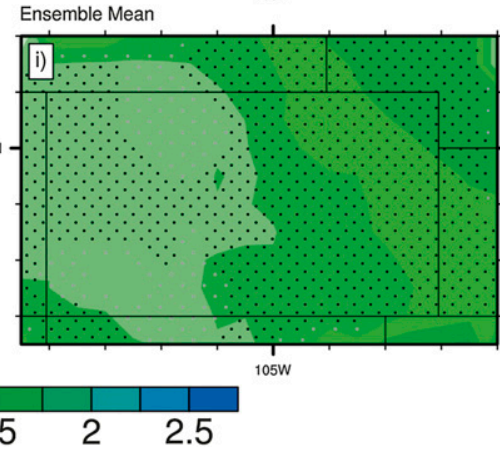

FIG. 4. Twenty-first-century minus twentieth-century mean JJA specific humidity $\left(\mathrm{g} \mathrm{kg}^{-1}\right)$ averaged over the twentieth century period (1971-2000) over Colorado from (a)-(h) the eight NARCCAP simulations and (i) their ensemble mean. Stippling indicates regions of significant differences as in Fig. 3.

models indicates the large uncertainty in the GHG-induced changes in extreme summertime precipitation over Colorado. Indeed, the difference in the average of the top 30 days (upper 1\%) between the twenty-first and twentieth centuries was not statistically significant, as determined from Monte Carlo resampling, in any of the eight models.

While we have focused on summer precipitation, aspects of the seasonal cycle of precipitation and how it is projected to change in the future are shown in Figs. S3 and S4 (in the supplemental material). Bimonthly estimates of precipitation averaged over Colorado plus border regions of the surrounding states are presented for the twentieth and twenty-first centuries and the difference between them (shaded) for the $80 \%, 90 \%$, 95\% (Fig. S3), 99\%, and the top 1\% (30 events) average (Fig. S4 in the supplemental material). The Livneh data indicate that there is a spring maximum (May-June) above the $95 \%$, but shifts toward a peak in summer (JulyAugust) from $90 \%$ to $80 \%$. The ability of the NARCCAP models to obtain this seasonal structure is mixed: most have a spring peak for the higher percentiles, but unlike observations, the spring peak is maintained for $80 \%-90 \%$ as well, while the GFDL-RCM3 exhibits a summertime maximum for all percentiles. Most models show increased precipitation in the twenty-first century relative to the twentieth century in winter (January-February and March-April) for all of the percentiles shown, with a robust increase in all of the models for more extreme events, that is, $99 \%$ and the average of the top $1 \%$. The enhanced winter precipitation in the NARCCAP simulations, particularly for more extreme events, confirms the findings of Dominguez et al. (2012). Consistent with Fig. 5, most of the models indicate decreased precipitation in summer (July-August) for all of the percentiles. The 

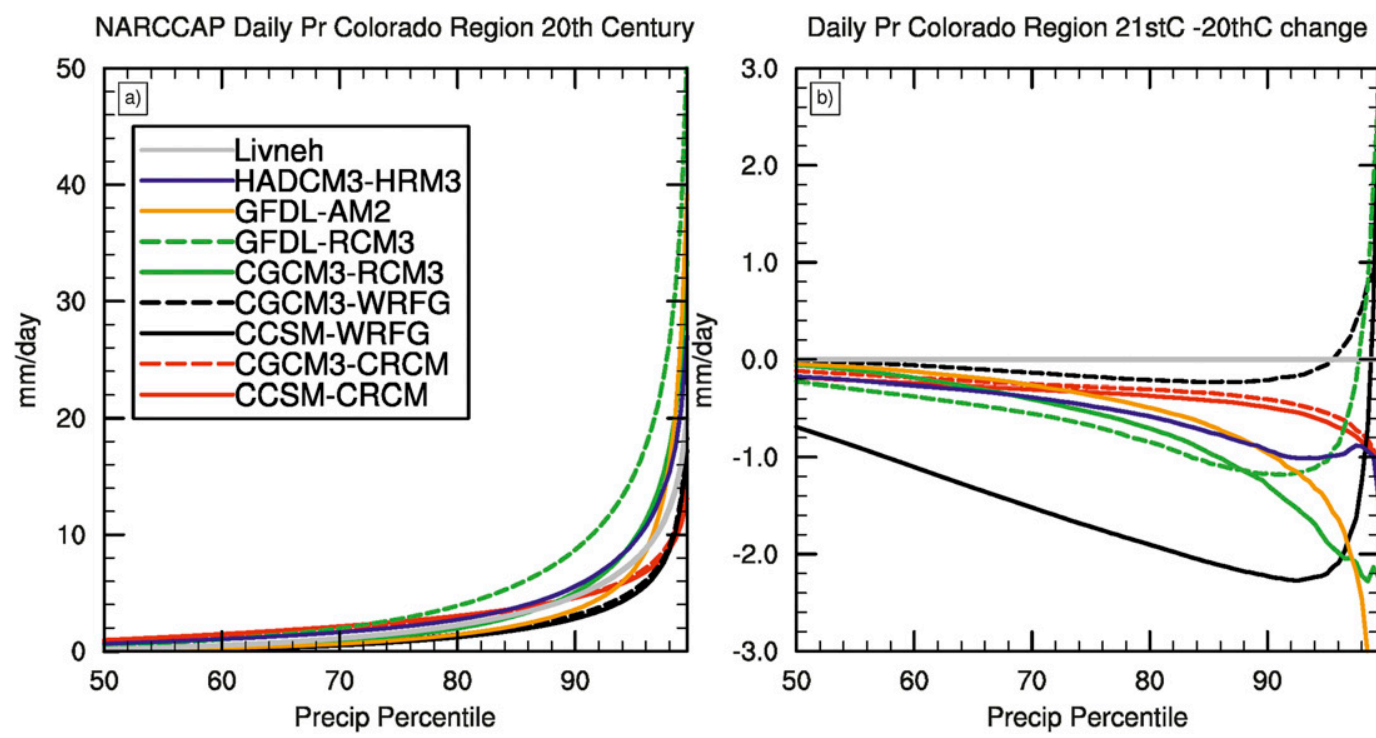

FIG. 5. The domain average of the daily precipitation amount in each grid square $\left(\mathrm{mm} \mathrm{day}^{-1}\right)$ shown as a function of the percentile (\%) during JJA for the NARCCAP simulations and the Livneh data in (a) the twentieth-century period and (b) NARCCAP twenty-first-century minus twentieth-century simulations. Values are plotted at every $0.5 \%$ from $50 \%$ to $99.5 \%$.

twenty-first-century minus twentieth-century values are more variable across both the models and percentiles during other seasons.

\section{Summary and conclusions}

The regional climate models within NARCCAP generally indicate drier summers in the future over much of Colorado and the border regions of the adjoining states. The change in the domain average of the local daily precipitation distributions indicates a decrease in precipitation for all of the models through the 95th percentile without a clear signal for the most extreme $(>99 \%)$ events. However, it may be necessary to have a very large sample size to detect changes in extremes, which by definition are rare events. Even with an increase in the surface specific humidity, our results suggest that the general notion that extreme precipitation events will increase in the future may be difficult to detect or may not occur everywhere. Changes in local and large-scale processes, such as a warming aloft and increased vertical stability and the reduction in easterly upslope flow (Mahoney et al. 2013), the poleward expansion of the Hadley cell/subtropical dry zones (e.g., Lu et al. 2007; Seager et al. 2007), and a delay in the North American monsoon limiting precipitation during JJA (Cook and Seager 2013), could diminish the mean summer rainfall and the number/intensity of heavy precipitation events despite an increase in the surface specific humidity. Thus, while increases in moisture may enhance the most extreme events, as indicated by the probable maximum precipitation (Kunkel et al. 2013), it is unclear whether that will be realized over portions of the western United States.

Even with improved resolution relative to GCMs, the 50-km NARCCAP simulations are still limited in resolving orographic effects, which may lead to biases in their sensitivity to climate change (e.g., Gao et al. 2011). Simulations with an order of magnitude higher resolution $(<\sim 5 \mathrm{~km})$ hold promise for resolving localized precipitation events and how they may change in the future (Rasmussen et al. 2011; Mahoney et al. 2012, 2013).

Acknowledgments. We thank the U.S. Bureau of Reclamation for their scientific interest and financial support for this project. We also wish to thank Linda Mearns, Seth McGinnis, and Melissa Bukovsky from the NARCCAP project for providing the RCM data and for guidance in how to best use it and Ben Livneh for providing the gridded precipitation data.

\section{REFERENCES}

Bukovsky, M. S., 2012: Temperature trends in the NARCCAP regional climate models. J. Climate, 25, 3985-3991.

Cook, B. I., and R. Seager, 2013: The response of the North American monsoon to increased greenhouse gas forcing. J. Geophys. Res. Atmos., 118, 1690-1699, doi:10.1002/jgrd.50111.

Daly, C., R. P. Neilson, and D. L. Phillips, 1994: A statisticaltopographic model for mapping climatological precipitation over mountainous terrain. J. Appl. Meteor., 33, 140-158. 
Dominguez, F., E. Rivera, D. P. Lettenmaier, and C. L. Castro, 2012: Changes in winter precipitation extremes for the western United States under a warmer climate as simulated by regional climate models. Geophys. Res. Lett., 39, L05803, doi:10.1029/ 2011 GL050762.

Field, C. B., and Coauthors, Eds., 2012: Managing the Risks of Extreme Events and Disasters to Advance Climate Change Adaptation. Cambridge University Press, 582 pp.

Gao, Y., J. A. Vano, C. Zhu, and D. P. Lettenmaier, 2011: Evaluating climate change over the Colorado River basin using regional climate models. J. Geophys. Res., 116, D13104, doi:10.1029/2010JD015278 .

_ , L. R. Leung, E. P. Salathé Jr., F. Dominguez, B. Nijssen, and D. P. Lettenmaier, 2012: Moisture flux convergence in regional and global climate models: Implications for droughts in the southwestern United States under climate change. Geophys. Res. Lett., 39, L09711, doi:10.1029/2012GL051560.

Gutowski, W. J., and Coauthors, 2010: Regional extreme monthly precipitation simulated by NARCCAP RCMs. J. Hydrometeor., 11, 1373-1379.

Kanamitsu, M., W. Ebisuzaki, J. Woollen, S.-K. Yang, J. J. Hnilo, M. Fiorino, and G. L. Potter, 2002: NCEP-DOE AMIP-II Reanalysis (R-2). Bull. Amer. Meteor. Soc., 83, 1631-1643.

Kunkel, K. E., T. R. Karl, D. R. Easterling, K. Redmond, J. Young, X. Yin, and P. Hennon, 2013: Probable maximum precipitation and climate change. Geophys. Res. Lett., 40, 1402-1408, doi:10.1002/grl.50334.

Leung, L. R., Y. Qian, X. Bian, W. M. Washington, J. Han, and J. O. Roads, 2004: Mid-century ensemble regional climate change scenarios for the western United States. Climatic Change, 62, 75-113.

Livneh, B., E. A. Rosenberg, C. Lin, B. Nijssen, V. Mishra, K. M. Andreadis, E. P. Maurer, and D. P. Lettenmaier, 2013: A long-term hydrologically based dataset of land surface fluxes and states for the conterminous United States: Update and extensions. J. Climate, in press.

Lu, J., G. Vecchi, and T. Reichler, 2007: Expansion of the Hadley cell under global warming. Geophys. Res. Lett., 34, L06805, doi:10.1029/2006GL028443.

Mahoney, K., M. A. Alexander, G. Thompson, J. J. Barsugli, and J. D. Scott, 2012: Changes in hail and flood risk in highresolution simulations over the Colorado Mountains. Nat. Climate Change, 2, 125-131, doi:10.1038/nclimate1344.

_ — - J. D. Scott, and J. Barsugli, 2013: High-resolution downscaled simulations of warm-season extreme precipitation events in the Colorado Front Range under past and future climates. J. Climate, 26, 8671-8689.

Maurer, E. P., A. W. Wood, J. C. Adam, D. P. Lettenmaier, and B. Nijssen, 2002: A long-term hydrologically based dataset of land surface fluxes and states for the conterminous United States. J. Climate, 15, 3237-3251.

McAfee, S. A., J. L. Russell, and P. J. Goodman, 2011: Evaluating IPCC AR4 cool-season precipitation simulations and projections for impacts assessment over North America. Climate Dyn., 37, 2271-2287.

Mearns, L. O., W. Gutowski, R. Jones, R. Leung, S. McGinnis, A. Nunes, and Y. Qian, 2009: A regional climate change assessment program for North America. Eos, Trans. Amer. Geophys. Union, 90, 311-312.

— , and Coauthors, 2012: The North American Regional Climate Change Assessment Program: Overview of phase I results. Bull. Amer. Meteor. Soc., 93, 1337-1362.

Meehl, G. A., and Coauthors, 2007: Global climate projections. Climate Change 2007: The Physical Science Basis, S. Solomon et al., Eds., Cambridge University Press, 747-845.

Mesinger, F., and Coauthors, 2006: North American regional reanalysis. Bull. Amer. Meteor. Soc., 87, 343-360.

Rasmussen, R., and Coauthors, 2011: High resolution coupled climate-runoff simulations of seasonal snowfall over Colorado: A process study of current and warmer climate. $\mathrm{J}$. Climate, 24, 3015-3048.

Ray, A. J., G. M. Garfin, M. Wilder, M. Vásquez-León, M. Lenart, and A. C. Comrie, 2006: Applications of monsoon research: Opportunities to inform decision making and reduce regional vulnerability. J. Climate, 20, 1608-1627.

Seager, R., and G. A. Vecchi, 2010: Greenhouse warming and the 21st century hydroclimate of southwestern North America. Proc. Natl. Acad. Sci. USA, 107, 21277-21282, doi:10.1073/ pnas.0910856107.

_ , and Coauthors, 2007: Model projections of an imminent transition to a more arid climate in southwestern North America. Science, 316, 1181-1184, doi:10.1126/science.1139601.

Wang, S.-Y., R. R. Gillies, E. S. Takle, and W. J. Gutowski Jr., 2009: Evaluation of precipitation in the Intermountain Region as simulated by the NARCCAP regional climate models. Geophys. Res. Lett., 36, L11704, doi:10.1029/ 2009GL037930.

Wehner, M. F., 2013: Very extreme seasonal precipitation in the NARCCAP ensemble: Model performance and projections. Climate Dyn., 40, 59-80, doi:10.1007/s00382-012-1393-1.

— R. Smith, P. Duffy, and G. Bala, 2010: The effect of horizontal resolution on simulation of very extreme US precipitation events in a global atmosphere model. Climate Dyn., 32, 241-247, doi:10.1007/s00382-009-0656-y.

Yin, J. H., 2005: A consistent poleward shift of the storm tracks in simulations of 21st century climate. Geophys. Res. Lett., 32, L18701, doi:10.1029/2005GL023684. 